\title{
Time required for caring: an experience from the Nursing process
}

\begin{abstract}
Background: Nursing diagnoses are identified, in light of the NANDA, then by observation and monitoring of care interventions, the nursing time required for professional and auxiliary care is determined; understanding the real time, as a measurement parameter of the action and the ideal time contextualized with the complexity of care. The times are socialized and validated, with the nursing professionals, in the manner of expert judgment from the evidence; the time to perform each of the care interventions is redefined.
\end{abstract}

Objective to reveal the time required of nursing personnel to provide close attention to the needs of the human being, from the application of the Nursing Process.

Methods: Within the framework of an experience in practice, the time required for care is carried out, the Puerta C AM1 method is adopted, which contemplates the assessment, planning and diagnosis and implementing interventions, as well as the determination of the time for care and other actions of nursing actions, valuation is carried out with 43 care subjects hospitalized in a Health Institution of the First Level of Care.

Results: We identified 25 nursing diagnoses and 46 care actions carried out in a time of 440 minutes of which $31.2 \%$ by nursing professional and $68.8 \%$ by auxiliaries. However, if the actions are assigned according to the protocols, the time is increased to 593 minutes with a longer time for professional nursing care. Conclusion: It requires a longer time for nursing care actions if the needs of patients are valued and recognized, as well as actions to support care and service management. The Nursing Care Process is the method to calculate the nursing time for each patient, from the assessment, diagnosis, prioritization, planning, execution and evaluation of care actions.

Keywords: Nursing administration research, nursing care, patient-centred care, patient care planning, nursing process
Volume 5 Issue 4 - 2018

\author{
Ana Margarita Puerta Cataño,' Dora Lucia \\ Gaviria Noreña ${ }^{2}$ \\ 'Enfermera Magíster en Salud Pública, Docente de la Facultad de \\ Enfermería de la Universidad de Antioquia, Colombia \\ ${ }^{2}$ Enfermera Magíster en Salud Colectiva, Especialista en \\ Epidemiología, Docente de la Facultad de Enfermería de la \\ Universidad de Antioquia, Colombia
}

\begin{abstract}
Correspondence: Dora Lucia Gaviria Noreña, Enfermera Magíster en Salud Colectiva, Especialista en Epidemiología, Docente de la Facultad de Enfermería de la Universidad de Antioquia, Colombia, Email dora.gaviria@udea.edu.co
\end{abstract}

Received: April 25, 2018| Published: August 21, 2018

\section{Introduction}

Know the nursing staff required for care, is one management challenges, since it must analyze progress scientists technological and discipline in the social, economic and political context in which people live, families and communities and the demands of social and health services. As Hurts expresses it, ${ }^{2}$ have been identified methods for calculating nursing staff as professional judgment by experts, the method of nurses per occupied bed, the analysis of the dependence of the degree of complexity of care and quality of activities, task-timed activity method and, finally, those based on regression analysis. The method proposed here is done following the Nursing Process - PAE complemented by the actions that support care. Today the challenge is greater when it is declared to the nursing, by organism s such as the World Health Organization and the International Council of Nursing -ICN- guarantor of the right to health and the achievement of the Sustainable Development Goals; is effective by providing quality care to people of all ages, and perform action ones of health promotion and disease prevention. WHO estimates that nurses and midwives account for almost half of all health workers worldwide. However, for all countries to achieve Sustainable Development Goal 3 on health and well-being, WHO estimates that by the year 2030 there will be an additional 9 million nurses and midwives around the world. ${ }^{3}$

For its part Greenberg, PB ., ${ }^{4}$ ratify the importance of having the right nursing staff to improve equity and access to health services, overcome the inequalities of the most vulnerable and excluded people, families and human groups, better serve populations in pandemic situations and natural disasters.

McHugh MD, Berez J, Small DS. ${ }^{5}$ confirm that hospitals with more nurses have less likely to readmissions and sanctions; Patterson ${ }^{6}$ For its part, it examines the literature on the proportion of nurse patients, to establish excellence in care and affirms that while using innovative strategies such as decreasing hospital stays, having a recruitment process with staff retention and having a long-term policy for the planning of the personnel.

In Colombia, Law 1164 of $2007^{7}$ which establishes the provisions of human talent in health, places as a priority the regulation of an information system that integrates the levels and competencies of all health personnel, which equitably serves the population that requires their services. The Ministry of Health and Social Protection ${ }^{8}$ emphasizes the need to develop a system that includes demand analysis focused on the needs of the population; the characterization of the offer that dimensions, among others, the health personnel with their performance categories; and the incentive approach that is based on pertinent and truthful information.

In this sense, this work provides another look for the study, analysis and argument the coefficient of personal of professional and support from the context nurse, also seeks to answer the question of ¿How nurses are estimated to provide care from the needs of people, families and groups? 


\section{Methodology}

Case study, adopts the Puerta C AM method, ${ }^{9}$ which includes assessment, planning, and implementing interventions and determination of the time care and other nursing actions; it is done from the valuation of 43 Care subjects hospitalized in the First Level Care Institution. Nursing diagnoses are identified, in light of the NANDA.

In addition, by observation and monitoring of care interventions, the nursing time required by category is determined: professional and auxiliary; understanding the real time, a measurement parameter of the action in minutes at the moment in which the record is observed and made; the ideal time involves a process where the information obtained is analyzed and monitored with the number of care subjects as needed, to adjust the time to a figure that is close to what is required to satisfy the need is . The reports are sent to the nursing directives to be taken into account in the instances where nursing care protocols and standards are determined.

The adopted method prioritizes central aspects of the Nursing Process -PAE- from the assessment, the formulation of the diagnoses and the plan of action or of the interventions. From the didactic the first moment includes, the recognition of the institutional and social context, documentary review, structured interviews regarding human talent policies, if required.

In a second moment, for fifteen weeks and in the time that a teacher and some students Course Management of nursing, University of Antioquia, develop their practice to the institution, the assessment to identify subjects care needs hospitalized; and determine the diagnoses and nursing and interventions required and the real and ideal time to execute them, and take into account the orientations of the NANDA. ${ }^{10}$ Real time is understood as timed in each action and idealized time contextualized and according to nursing standards.

Besides, the actions of nursing professional and nursing assistant are identified for the support of care and the time in minutes required for each time it is performed. The study collects the contextualized particularities, according to the work load executed, the situation of the patients, or the complexity of the service, it is not a study of time and movement of the nursing staff.

The process analysis, interpretation, and validation of information is performed once reflection in applying the PAE, teacher and student interaction continues to verify the information and look consistencies or not the guidelines of nursing and health service : the attention processes, the operating norms, the evaluation indicators, the norms established in the institution and the socio-demographic and epidemiological comparison, in addition they analyze the discrepancies, departures, or separations in the results with the established in the institution.

Then socialization meetings and validation of the information are carried out with the nursing professionals, heads of the hospitalization service and the pertinent adjustments are made, if needed; diagnostics regarding nursing interventions demanded and required time nurse or nursing assistant. This method is called analysis by consensus from the evidence; it is a judgment of experts where they are immersed in the daily task of the subject investigated.

\section{Results}

The list below shows 25 nursing diagnoses identified with the
43 care subjects hospitalized at different times, during the fifteen weeks of the study. Allowing in the future to approach other studies with similar methodologies; it is clear that the results are applicable only to the subject of this study only care because you cannot make inferences in other areas, but if you can replicate the methodology in other institutions. They identify themselves 46 actions or interventions that conform to the NIC taxonomy ${ }^{11}$ made for the care of hospitalized people, See Table 1. It stipulates the total real time required by the nursing team to carry out the Actions, so by the time it is identified that provide auxiliary $68.9 \%$ and $31.1 \%$ the of professionals the time care, however it must take into account that some nursing actions not being performed and observed that are part the care plan, which means that it can vary the time and increases the requirement for staff, if they are carried out.

Table I Identified Diagnostics

\begin{tabular}{|c|c|}
\hline & Identified diagnostics \\
\hline I & Anxiety R/C unknown forecast \\
\hline 2 & Anxiety $R / C$ inability to work \\
\hline 3 & Alteration of well-being $\mathrm{R} / \mathrm{C}$ heartburn by regurgitation \\
\hline 4 & Alteration of well-being $R$ /C pain \\
\hline 5 & $\begin{array}{l}\text { High risk of alteration in self-care } R / C \text { deficit in the knowledge of } \\
\text { the disease, medication, signs and symptoms of complications }\end{array}$ \\
\hline 6 & High risk of infection $\mathrm{R} / \mathrm{C}$ invasive procedures \\
\hline 7 & Impairment of physical mobility R /C edema and pain \\
\hline 8 & Deficit of self-care R /C mobility limitations \\
\hline 9 & Deficit Self-care R /C pain \\
\hline 10 & $\begin{array}{l}\text { Intolerance to R / C activity or insufficient oxygenation S / A tissue } \\
\text { hypoxia and pulmonary congestion }\end{array}$ \\
\hline 11 & Ineffective airway cleaning R/C difficulty coughing \\
\hline 12 & Deficit due to fluid volume alteration $\mathrm{R} / \mathrm{C}$ vomiting and diarrhea \\
\hline 13 & $\begin{array}{l}\text { Decrease in gaseous exchange } R / C \text { increase in pulmonary secretions } \\
S / A \text { infectious processes }\end{array}$ \\
\hline 14 & $\begin{array}{l}\text { Decrease in gaseous exchange } R / C \text { presence of pulmonary fluid S/A } \\
\text { heart failure }\end{array}$ \\
\hline 15 & Decrease in gas exchange $R / C$ narrowing of the airway \\
\hline 16 & $\begin{array}{l}\text { Decrease in cardiac output } \mathrm{R} / \mathrm{C} \text { decrease in the strength of cardiac } \\
\text { contraction }\end{array}$ \\
\hline 17 & $\begin{array}{l}\text { Intolerance to activity due to fatigue and dyspnea R /C decreased } \\
\text { cardiac output }\end{array}$ \\
\hline 18 & Increase in extra vascular fluid $\mathrm{R} / \mathrm{C}$ heart failure as a pump \\
\hline 19 & $\begin{array}{l}\text { Decreased urinary output } R / C \text { renal failure due to decreased tissue } \\
\text { irrigation S/A heart failure }\end{array}$ \\
\hline 20 & $\begin{array}{l}\text { Risk of electrolyte imbalance R/C increase in the loss of ions and } \\
\text { water in the urine }\end{array}$ \\
\hline 21 & Anxiety R/C term gestation \\
\hline 22 & Fear R/C possible loss of uterine content \\
\hline 23 & Risk of alteration in cutaneous continuity R/C immobility \\
\hline 24 & $\begin{array}{l}\text { Risk of electrolyte imbalance R/C increase in loss and decrease of } \\
\text { inputs }\end{array}$ \\
\hline 25 & Risk of alteration in nutrition $\mathrm{R} / \mathrm{C}$ lack of appetite \\
\hline
\end{tabular}


Regarding the total ideal time to invest by the nursing team, in actions to be carried out for care, for one time or another, the situation shows that since it should be, it requires more time for nursing professionals to care, in a percentage of 67.8 unlike 31.1 that have in real time.

Likewise, the actions of support for care show, See Table 2, a greater participation of the nursing professional especially in the planning of care, the preparation of the Kardex and the medication card. Now, the ward secretary invests more time in the operational management for the acquisition of the resources and the return of the same, in which 60 minutes are spent at a time in the latter.

For their part, the nursing assistants participate with their time in the realization of actions that involve the professional and the secretary of the service. The time found for cleaning the unit is striking; 30 minutes at a time. Table 3

Table 2 Nursing actions by personnel category and average time in minutes performed only. First level hospital

\begin{tabular}{|c|c|c|c|c|c|}
\hline & \multirow{2}{*}{ Actions } & \multicolumn{2}{|l|}{ Real Time per patient } & \multicolumn{2}{|c|}{ Ideal time per patient } \\
\hline & & Professional & Assistant & Professional & Assistant \\
\hline I & Attend the changes manifested by the Newborn & - & 25 & 25 & - \\
\hline 2 & Apply oral and intramuscular medications & - & $10 *$ & - & $10 *$ \\
\hline 3 & Assist in the feeding. & - & 10 & - & $14 *$ \\
\hline 4 & Assist in the change of position every 2 hours. & - & 5 & - & $10 *$ \\
\hline 5 & Apply lotion or cream on the skin every 12 hours & - & 5 & - & $10 *$ \\
\hline 6 & Apply Blood Products & - & 7 & 30 & 0 \\
\hline 7 & Bathe the Newborn & - & 20 & & 20 \\
\hline 8 & Perform bladder catheterization & II & 15 & II & 10 \\
\hline 9 & Channel veins & - & 8 & 5 & 10 \\
\hline 10 & Make cures and skin care & 15 & 15 & 30 & 15 \\
\hline II & Educate and inform the family about care & 12 & 10 & 12 & 12 \\
\hline 12 & Perform Postural drainage & this activity was not observed & $\begin{array}{l}\text { this activity was not } \\
\text { observed }\end{array}$ & 20 & - \\
\hline 13 & Perform Glucometry & $5^{*}$ & $2^{*}$ & $5^{*}$ & $2^{*}$ \\
\hline 14 & Teach the risks of immobility & 3 & $\begin{array}{l}\text { this activity was not } \\
\text { observed }\end{array}$ & 5 & 5 \\
\hline 15 & Perform Electrocardiograms & 8 & - & 10 & - \\
\hline 16 & Teach about wandering & 5 & 5 & 10 & 5 \\
\hline 17 & Evaluate feeding patterns and fluid intake & 10 & - & 10 & - \\
\hline 18 & $\begin{array}{l}\text { Teach about the disease, the treatment and the objectives to } \\
\text { improve the state of health. }\end{array}$ & 12 & 10 & 15 & 10 \\
\hline 19 & Teach protective measures to prevent falls. & $3^{*}$ & $5 *$ & $15^{*}$ & $15^{*}$ \\
\hline 20 & Teach breathing exercises & 8 & - & 8 & $5 *$ \\
\hline 21 & Encourage participation in self-care activities. & $7 *$ & $5 *$ & $15^{*}$ & $5 *$ \\
\hline 22 & $\begin{array}{l}\text { Facilitate the exposure of feelings through active listening, } \\
\text { questions and reflection. }\end{array}$ & 5 & 5 & 15 & 5 \\
\hline 23 & Assess pressure points on the skin. & 5 & 3 & $5^{*}$ & $5 *$ \\
\hline 24 & Make the entry to the person & 10 & 14 & 15 & 10 \\
\hline 25 & Gastric naso catheterization & 7 & 7 & 10 & 5 \\
\hline 26 & Perform enema & - & 15 & - & 15 \\
\hline 27 & Massage bony prominences & - & 5 & - & $5^{*}$ \\
\hline 28 & Perform Fetal Monitoring & - & 30 & $30 *$ & - \\
\hline 29 & Make Nebulisations & - & $12 *$ & - & $12 *$ \\
\hline 30 & Apply intravenous therapy & - & 10 & - & $20 *$ \\
\hline
\end{tabular}


Table continued...

\section{Actions}

Measure ingestion and elimination of liquids

Weigh daily

Perform passive exercises.

Apply Respiratory Therapy

Take laboratory tests

Use physical measures, massages to increase well-being.

Assess the general condition and follow-up of care

Assess the pain and apply the therapy.

Value tolerance to activity.

Assess vascular and neurological involvement

Rate sleep patterns

Monitor side effects of medications

Assess Vital signs.

44 Analyze test results and communicate abnormalities

Rate signs of infection.

Assess the mental state: restlessness, coherence and alertness.

Total time in minutes

Total time in hours

\section{Real Time per patient}

- 5

$-$

this activity was not observed

this activity was not observed

5

$-$

2

2

$-\quad 2$

3

6 6*

$3^{*}$

$-\quad 3$

137

31.1 this activity was not observed

this activity was not observed

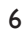

5

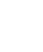

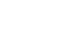

2

(2)

$6 *$

$-$

3

3

303

68.9

\begin{tabular}{|c|c|}
\hline \multicolumn{2}{|c|}{ Ideal time per patient } \\
\hline- & 5 \\
\hline- & 3 \\
\hline- & 15 \\
\hline 15 & - \\
\hline 7 & $10 *$ \\
\hline 5 & 15 \\
\hline $15^{*}$ & $5^{*}$ \\
\hline $10 *$ & $5^{*}$ \\
\hline $5^{*}$ & $2 *$ \\
\hline $10 *$ & $2^{*}$ \\
\hline $5^{*}$ & $2^{*}$ \\
\hline $10 *$ & $2 *$ \\
\hline $4^{*}$ & $6 *$ \\
\hline $5^{*}$ & - \\
\hline $5^{*}$ & $5^{*}$ \\
\hline $5^{*}$ & $2 *$ \\
\hline 402 & 191 \\
\hline 67.8 & 32.2 \\
\hline
\end{tabular}

* Time for an action, if repeated several times in 24 hours, multiply by the number that is repeated

Table 3 Nursing care support* and time in minutes for each time according to personnel category, Hospitalization service. First level

\begin{tabular}{|c|c|c|c|}
\hline \multirow[t]{2}{*}{ Actions } & \multicolumn{3}{|c|}{ Time in minutes } \\
\hline & Nurse & Assistant & Secretary \\
\hline Deliver turn, each participant & 20 & 20 & 20 \\
\hline To assign activities & 7 & - & - \\
\hline Attend the person during the medical round & 20 & - & - \\
\hline Prepare and update the Kardex and records & 83 & - & - \\
\hline Update of medication cards (Audit) & 80 & - & - \\
\hline Update care plans (PAE included) & 91 & - & - \\
\hline Perform round of Nursing, per shift & 20 & 20 & - \\
\hline Request diets & 15 & - & 46 \\
\hline Process specialized laboratory exams. & - & - & 15 \\
\hline Verify the existence of resources & - & - & 15 \\
\hline Request missing resources & - & - & 60 \\
\hline Request medications for patients & 15 & - & 120 \\
\hline Make a refund of the existence of resources & 10 & - & 60 \\
\hline Send requests to pharmacy & - & 6 & 6 \\
\hline Perform process of inter consultations and referrals & 10 & - & 20 \\
\hline Confirm the exit of the subject of care & 5 & 5 & 5 \\
\hline Review Clinical History. & 8 & 8 & 8 \\
\hline Perform and monitor billing regulated & 2 & 3 & 40 \\
\hline Report administrative paperwork about graduation & 15 & 10 & - \\
\hline
\end{tabular}

Citation: Cataño AMP, Noreña DLG.Time required for caring: an experience from the Nursing process. Nurse Care Open Acces. $2018 ; 5(4): 258-263$. 
Table continued...

\begin{tabular}{llll}
\hline Actions & \multicolumn{2}{l}{ Time in minutes } \\
\hline Registrar subject egress care & 5 & 5 & 10 \\
Carry out terminal cleaning of the unit & - & 30 & - \\
Review inventories & 15 & 12 & 30 \\
To elaborate Other records: Hours worked, daily patient census, delivery diary & 20 & 15 & 48 \\
Total time in minutes & 441 & 134 & 8 \\
Total Time in Hours & 7.35 & 2.2 & 485 \\
\hline
\end{tabular}

Note: * Not all actions are included: support for care or for management, research and education

\section{Discussion}

The methods to estimate the time required for nursing actions, have this ongoing discussion do in practice in nursing and has become the cornerstone of management by favouring the an assignation of the personnel for the provision of the care. In this direction Hurst $\mathrm{K}$, quoted by Gaviria $\mathrm{N}^{12}$ provides, to have a method to know the $\mathrm{s}$ nursing activities and time, it is a reality that nurses should lead to a systematic planning of care, identifying needs and actions that can be predicted and monitored in day to day and that their results can be corroborated in other contexts. In line, this study assumes Nursing Process -PAE-, as the method for setting the times required care from the language and the international classification of nursing practice, which favours a job that can be applied in various contexts and ensure quality care.

Andrea B, ${ }^{13}$ Bruyneel L et al. ${ }^{14}$ \& Hanrahan NP et al. ${ }^{15}$ Neff DF et al. ${ }^{16}$ agree in affirming that achieving greater training, retention and maintenance of an adequate number of nursing staff for to confront better than the health level of the population in general. The difference in Colombia care is provided by the auxiliary staff with less training, have a high turnover of staff and flexibility in the type of contract makes more problematic the situation to achieve the ideal care while focusing on necessitates the patient and their families. In the study, the ideal time is doubled for the nursing professional, today in the Health Services Enabling Resolution 2003 of 2014, ${ }^{17}$ there is no national standard for the number of nurses ; auxiliary, professional and/or specialist per patient. What it leaves to the free interpretation of public and private employers.

Rothberg $\mathrm{MB}$, et al. ${ }^{18}$ corroborate how a cost-effective safety intervention is related by the proportion of nurse-patient staff, analyze the institutional profitability by comparing the proportions of nursepatient from 8: 1 to $4: 1$, the ratio being eight patients per nurse. Less expensive, but with the patient's mortality higher. The authors conclude that a patient safety intervention, has to do with patient to nurse ratios of 4: 1 it is reasonably profitable and more accepted. The construction of instruments that allow to know the nursing activities and the time required, are important but authors such as agree that these only reach to capture $40 \%$ of nursing work given its complexity and diversity in the context where it is provided; Therefore, from the Nursing Care Process, the real time for care can be visualized, which, added to the inventory of time to carry out actions supporting care, education, research and management, can lead to standards where the time required to perform all the functions required by professional work is determined. Thorsell et al. ${ }^{19}$ an analysis of Time In Care Needs (TIC-n) determines that dependency care to support the functions of everyday life, by decreasing the capacity des mobility and activity in older adults, makes it requires a longer time The actions of care to deal with the company, communication and other forms of assistance and support are not, visible and today require systematization.

On the other hand and added to the o exposed, it is good to hear the voice of the International Council of Nurses $\mathrm{ICN}^{20}$ in two senses, clarifies in the first place that the experiences show that greater training of nursing staff results in better results associated with the quality of health services in general and the satisfaction of patients and their families with care. And as a second, the $\mathrm{ICN}^{20}$ he states that there are demands from nurses who have been considered responsible for providing care. The issue of responsibility focuses on aspects of care that encompass the person and the team. Therefore, whatever the situation (that is, the context in which the errors occur), the nurse is responsible. Thus, reliable staffing is a critical element for nurses because it influences their ability to provide appropriate care. Responsibility increases in clinical contexts in which infrastructure and personnel are inadequate. Jaramillo $\mathrm{M}^{21}$ he says "in the System Colombiano of Health professionals, particularly nurses construct and reconstruct their values, principles and meanings, amid an uncertain and unstable context, where the accompaniment and address of the state bodies is focused more on the formulation of regulations and the control of resources that in job stability, training and hiring to establish safe and healthy working conditions". Even more, Alcaraz LG et al., ${ }^{22}$ reinforce. With regard to what nurses do in adult hospital wards, they point out three problems: the first has to do with training ; the second is the lack of knowledge of administrators, auditors and managers of health companies, about the purpose of nursing, its implications for well-being and life, and hospital costs, privileging the work of the nurse in the role of administrator of health rooms or services and the co adjuvant of other institutional administrative processes; and the third is the lack of a well-paid job offer. From the everyday, care is given in the midst of contrasts and contradictions; On the one hand, there are certainties in the face of the pressing need that a reliable nursing staff is a condition to save lives and guarantee the quality of care in health services; on the other hand, nursing work is not visible and hidden in both are assigned multiple functions from the administrative as well as secretarial, maintenance and billing actions that displace the real care essence of the profession. Therefore, among other arguments can be concluded, it is mandatory to recover the time for care and to perform all the functions that must fulfil the nursing staff in order to offer a quality and safe care as provided by the Patient Safety Policy in Colombia affirmation that deserves to join the voices of the nursing staff, of the caregivers, their families, the associations, the academy, in shouts that are raised before the health management bodies. And as a closure, the $\mathrm{ICN}^{20}$ guidelines are accepted for the year 2014 where he reiterates" greater well-trained human resources of nursing + good work environment $=$ quality health care. This simple equation, based on evidence, if applied globally or locally in 
the health system, is fundamental to understanding how to make the most of this vital resource that is nursing."

While the method allows us to have an approach from the subject of careful implementation of the SAP, identified the limitation related to the determination of time $\mathrm{d}$ and the care support actions and those carried out for the funcionamiento service as meetings, participation in various committees and projects laboration of management team and nursing education to internal and external customers, research, among others. For future studies is recommended that experience should be systematic daily and for a prudent period to ensure take possible changes that may occur over time, in terms of type of subjects care, their needs, their expectations and the requirements for the management of the service and the institution, and the demands of context from the political, economic, social and environmental, in its dynamic and historical dimension that affects the provision of nursing human talent. It is expected that at the end of a period, a year, for example, with the wealth of data obtained, regularities and precisions can be concluded in order to establish standards for care from the average time required for nursing, by category of personnel, to perform all the care interventions. While studies are inconclusive, but of value to show a reality that requires more hours spied research in different months of the year to capture all the peculiarities of the complexity of nursing work in the institution. Studies to determine the times required nursing, permit evaluate the care process and establish improvement placement towards quality, also from the theoretical knew rare can look and recovering interventionist actions 1 care as a construction with the other and for the other it is intentional and contextualized.

\section{Acknowledgments}

None.

\section{Conflict of interest}

The author declares that there is no conflict of interest.

\section{References}

1. Puerta Cataño AM. Nursing: Endowment plans from care, an achievable utopia. Faculty of Nursing University of Antioquia. Mexico.1998.

2. Hurst K. Selecting and applying methods for estimating the size and mix of nursing teams A systematic review of the literature commissioned by the Department of Health. United Kingdom. 2003

3. CIE Nursing Now Campaign of empowerment and support for nurses to overcome $21^{\text {st }}$ century health challenges.

4. Greenberg PB. Nurse-to-patient ratios: what do we know?. Policy Polit Nurs Pract. 2006;7(1):14-16.

5. McHugh MD, Berez J, Small DS. Hospitals with higher nurse staffing had lower odds of readmissions penalties than hospitals with lower staffing. HealthAff (Millwood). 2013;32(10):1740-1747.
6. Patterson J. The effects of nurse to patient ratios. Nursing Times. 2011;107(2):22-25.

7. Republic of Colombia law 1164 of 2007 by which dispositions are dictated in matter of the Human Talent in Health.

8. Ministry of Health. National School of Public Health. Program of support for the reform. Model of Supply and Demand of Human Resources in Health for Colombia. Medellín. Colombia.

9. Puerta Cataño AM, Gaviria Noreña DL, Duque Henao SL. Nursing time required for quality care. Investig Enferm Imagen Desarr. 2017;19(2):145159

10. North American Nursing Diagnosis A. NANDA-I nursing diagnoses: definitions and classification, 2013-20. Madrid: Elsevier; 2008.

11. Bulechek G, Butcher H, McCloskey J. Classification of Nursing Interventions (NIC). Spain. 2009

12. Gaviria-Noreña DL. Planning the required nursing personnel to respond to care needs. Invest Educ Enferm. 2013;31(1):116-124 .

13. Andrea B. The effect of staff turnover and the benefit of stability in the human resources of nursing. In: Nurses CIE, editor. Geneva Switzerland: CIE International Council of Nurses; 2010:1-38.

14. Bruyneel L, Van den Heede K, Diya L, et al. Predictive validity of the International Hospital Outcomes Study questionnaire: an RN4CAST pilot study. J Nurs Scholarsh. 2009;41(2):202-210.

15. Hanrahan NP, Kumar A, Aiken LH. Adverse events associated with organizational factors of general hospital inpatient psychiatric care environments. Psychiatr Serv. 2010;61(6):569-574.

16. Neff DF, Cimiotti JP, Heusinger AS, et al. Nurse reports from the frontlines: analysis of a statewide nurse survey. Nurs Forum. 2011;46(1):4-10.

17. Ministry of Health and Social Protection. Resolution 2003 of May 28, 2014. By which the procedures and conditions for registration of the Providers of Health Services and health services are defined. Bogotá DC, Colombia, 2014

18. Rothberg MB, Abraham I, Lindenauer PK, et al. Improving Nurse-to-Patient Staffing Ratios as a Cost-Effective Safety Intervention. Medical Care. 2005;43(8):785-791.

19. Thorsell KB, Nordstrom B, Nyberg P, et al. Measuring care of the elderly: psychometric testing and modification of the Time in Care instrument for measurement of care needs in nursing homes. BMC Geriatr. 2008;8:1-8.

20. International Council of Nurses CIE. Nurses: A force for change A vital resource for health Folder of information and action tools International Day of the nurse 2014

21. Jaramillo Mejía ÁM. Patient safety: meanings constructed by nursing professionals. Bello 2012-2013 Research work to qualify for the Master's degree in Collective Health Faculty of Nursing Universidad de Antioquia 2014.

22. Alcaraz López G, Zapata Herrera M, Gómez Gómez M, Tavera Agudelo E. Functions of the nursing professional in adult hospitalization rooms: Trying to give direct care. InvestEducEnferm. 2010;(1):43-53. 